\title{
Smoking experimentation and initiation among adolescent girls: qualitative and quantitative findings
}

\author{
Mimi Nichter, Mark Nichter, Nancy Vuckovic, Gilbert Quintero, Cheryl Ritenbaugh
}

\begin{abstract}
Objective-To use qualitative and quantitative findings to describe patterns of smoking experimentation and initiation among adolescent girls.

Design-Ethnographic in-person interviews, focus groups, telephone interviews, and a survey questionnaire were used over a one-year period. The paper reports on cross-sectional data drawn from a three-year longitudinal study.

Subjects and setting-205 girls participated in the survey and interviews during year 3 of the study. Girls were drawn from two urban high schools in Tucson, Arizona (USA), and were in grades 10 and 11 (mean ages 16 and 17 , respectively) during year 3.
\end{abstract}

Results-Overall, $30 \%(n=61)$ of informants reported that they currently smoked, $7 \%(n=15)$ were ex-smokers, and $63 \%$ ( $n=129)$ were "non-smokers". The most frequently cited reasons for smoking were stress reduction and relaxation. Several stress-inducing situations, including family environment, social relations with classmates, and schoolwork, are discussed. The notion of peer pressure is re-examined in the light of teenagers' experience that there is little overt pressure to initiate smoking. Consonant with notions of adolescent autonomy, the theme of independence in smoking initiation and continuation permeated girls' narratives about their smoking behaviour. Girls projected the image that they could control their cigarettes rather than have their cigarettes control them.

Conclusions-Smoking prevention and cessation programmes need to address and counter the smoking/relaxation association, which was identified as an important reason for smoking among adolescent girls. Questions typically used in surveys to measure smoking behaviour do not adequately define the smoking experience as described by teenagers.

(Tobacco Control 1997;6:285-295)

Keywords: adolescents, tobacco use, smoking initiation

Introduction

In contrast to dramatic declines in adult smoking that have occurred in the past two decades, smoking among adolescents has been on the increase since 1991. Prevalence of smoking among adolescents in grades 9-12 (ages 14-18 years) increased from $27.5 \%$ in 1991 to $30.5 \%$ in 1993 to $34.8 \%$ in $1995 .{ }^{1}$ Current rates of smoking among male and female adolescents in 1995 were reported to be $35.4 \%$ and $34.3 \%$, respectively. The age of onset of tobacco use has decreased substantially over the past 20 years, especially for girls. ${ }^{2}$ Also of concern is the fact that girls and young women, even those who are light smokers, often report symptoms of nicotine dependence. ${ }^{3}$ Thus, greater efforts are needed to prevent smoking initiation among adolescent girls.

Although it is widely recognised that multiple factors influence tobacco use, there are major gaps in our understanding of smoking uptake among teenagers. ${ }^{4}$ Despite extensive research on correlates and antecedents of adolescent smoking, relatively little is known about how adolescents view smoking in the context of their everyday lives. The focus of much research has been the identification of predictors of risk behaviours, to the exclusion of an understanding of the social context in which such behaviour is engaged and the degree to which such behaviours are viewed as risky by adolescents themselves.

Data on adolescent smoking have been predominately collected through surveys in which adolescents are asked to report on their attitudes and behaviours in response to researcher-specified categories. A review of 46 tobacco-related journal articles revealed that only $5 \%$ of these studies used structured, open-ended interviews with adolescent informants. ${ }^{5}$ Several researchers have acknowledged the limitations of previous studies and have argued for the need for qualitative research on adolescent health, so that the voices of teenagers can be heard. ${ }^{6-9}$

The study upon which this paper is based incorporated a qualitative data collection stage which informed the development of a series of survey questions. In this paper, we report on both the qualitative and quantitative findings to describe patterns of experimentation and initiation into smoking among adolescent girls in two urban high schools. Examined is the extent to which smoking is viewed as normative behaviour among these teenagers. Reasons given for starting to smoke are considered, most notably smoking as a mechanism for reducing stress related to family environment, social alienation, and academic pressure. Peer pressure, a factor which has commonly been associated with smoking onset in the expert literature, is re-examined from an 
adolescent perspective in which autonomy is highly valued. Next, we turn to a consideration of social contexts in which smoking occurs, such as smoking at parties while consuming alcohol. Finally, perceptions of health risks associated with smoking among teenagers who do and do not smoke are examined. Throughout the paper, attention is paid to the semantics of smoking discourse, particularly how adolescents describe their own and peers' smoking behaviours and the social contexts in which smoking occurs.

\section{Methods}

Data drawn upon in this paper are from year 3 of a three-year longitudinal study on smoking, dieting, and food intake among adolescent girls in Tucson, Arizona (USA). The study, known locally as the Teen Lifestyle Project, began with a cohort of 279 girls consisting of 158 eighth graders (aged 13-14) and 121 ninth graders (aged 14-15). A convenience sample of girls was recruited from among eighth and ninth graders attending two junior high schools and two high schools in Tucson. One junior high school and one high school were located in urban, lower-to-middle income neighbourhoods. The other junior high school and one high school were located in suburban Tucson, with a student population from middle-toupper-middle income families. This sampling permitted us to recruit students from a range of economic backgrounds.

The project was introduced to girls in physical education (PE) classes at each of the schools. Although the classes themselves were not gender-segregated, girls were asked to attend our presentation rather than participate in the day's class. All girls agreed to attend the information session, which described the project as an opportunity for students to express their opinions about issues important to teenagers. Approximately $80 \%$ of girls chose to participate and returned consent forms signed by themselves and a parent or guardian.

This paper reports on cross-sectional data from the third year of the study and includes 205 adolescent girls. In year 3, the mean age of the 10th graders was 16.02 (SD 0.44) and 16.99 (SD 0.49) for 11 th graders. In terms of ethnicity, $68 \%$ of the sample were white, $13 \%$ were Mexican American, 3\% were Asian American, and 3\% were Native American. The remaining $13 \%$ of informants did not categorise themselves into any ethnic group. There were no significant differences between the ethnic backgrounds of the girls who joined the study in year 1 and those who remained at year 3.

In terms of the educational status of the parents, $7 \%$ of the mothers had not graduated from high school, $28 \%$ were high school graduates, $20 \%$ had some college or vocational training, 30\% were college graduates, and $15 \%$ had education beyond college. With regard to the fathers, $6 \%$ had not graduated from high school, $23 \%$ were high school graduates, $16 \%$ had some college or vocational training, $30 \%$ had a four-year college degree, and $25 \%$ had education beyond college. There were no significant differences between parental education of the girls who joined the study at year 1 and those who remained at year 3 .

Multiple methods were used in this study. In year 3, each girl participated in one in-depth, semi-structured ethnographic interview which took approximately one hour. Eight field researchers trained in ethnographic interviewing conducted the interviews. An interview script was devised to ensure a level of standardisation in data collection. Because the ethnographic method is hermeneutic in approach, new questions were added to the script when our knowledge of a topic increased as a result of the interview experience.

Each girl completed a 113-item survey questionnaire. In addition, focus groups were held with girls who were smokers to discuss issues relevant to this group. In year 3, 10 focus groups were conducted, with each group consisting of six girls. Interviews, survey questionnaires, and focus groups all took place in the high schools. Girls were excused from class to participate in project activities. Telephone interviews were conducted twice during the school year to ascertain smoking behaviour in the previous two weeks.

All individual and focus group interviews were tape-recorded and were later transcribed using Notebook software. This software permits classification and retrieval of transcripts on the basis of themes, which facilitates comparison of discourse across participants. Themes were established by the research team on the basis of questions in the interview script and themes that emerged as the cycle of interviews progressed. Transcription of all of the taped interviews and focus groups were done by project staff, many of whom had also conducted interviews with the girls. To facilitate the data analysis process, regular meetings were held to discuss emergent themes and problems with questions, and to consider the addition of new questions to the interview script and for focus group discussions.

Ethnographic research was conducted to enable the researchers to gather data on the way in which smoking was discussed by girls. Through ongoing ethnography and analysis of their discourse, the authors identified new variables for study and inclusion in the survey over the three years. The survey instrument was therefore modified from year 1 to year 3, although core questions remained in every version of the survey. The semi-structured individual interviews and focus group interviews facilitated the identification of question frames and appropriate language and probable ranges of responses for use on the survey instrument. For example, the different categories of smoking behaviour (see table 2) that were used on the survey questionnaire were derived from interviews and a contextual appreciation of adolescent smoking patterns. These classifications are discussed in greater detail later in this paper. Response categories used in tables 3 and 6 were also derived from common themes which emerged during the 
Table 1 Responses to the survey question: "In your opinion, what percentage of girls in your grade at this schoolladult women in the US smoke cigarettes?" ( $n=205)$

\begin{tabular}{|c|c|c|c|c|}
\hline & \multicolumn{2}{|c|}{ Girls in your grade } & \multicolumn{2}{|c|}{ Adult women } \\
\hline & $n$ & $\%$ & $n$ & $\%$ \\
\hline Less than $10 \%$ & 1 & 0.5 & 1 & 0.5 \\
\hline 10 to $25 \%$ & 50 & 24 & 25 & 12 \\
\hline 26 to $50 \%$ & 69 & 34 & 87 & 43 \\
\hline 51 to $75 \%$ & 64 & 31 & 58 & 28 \\
\hline 75 to $90 \%$ & 21 & 10 & 29 & 14 \\
\hline More than $90 \%$ & 1 & 0.5 & 4 & 2 \\
\hline
\end{tabular}

Table 2 Responses to the survey question: "Which statement best describes you with regard to your smoking behavior?" $(n=205)$

\begin{tabular}{lrr}
\hline & $n$ & $\%$ \\
\hline I'm not a smoker but I'll have a cigarette every once in a while & 31 & 15 \\
I just smoke when I'm partying & 8 & 4 \\
I smoke on a fairly regular basis but I don't need to & 10 & 5 \\
I've got to have my cigarettes & 12 & 6 \\
I'm an ex-smoker & 15 & 7 \\
I don't smoke & 129 & 63 \\
\hline
\end{tabular}

interviews. Interview data also provided clarification of the meaning of survey responses.

\section{Results}

PERCEIVED PREVALENCE OF SMOKING

Numerous studies have reported that adolescents greatly overestimate the prevalence of cigarette smoking among adolescents and adults alike when compared with the actual statistics. ${ }^{1011}$ Researchers have concluded that relatively high estimations of smoking prevalence are predictive of smoking onset as well as increases in smoking. ${ }^{12-14}$ To assess this issue among girls in our study, we asked informants to respond to the following survey question: "In your opinion, what percentage of girls in your grade at this school smoke cigarettes?" A separate question queried the perceived prevalence of smoking among adult women in the United States. Responses from both these questions are shown in table 1 .

More than $40 \%$ of girls in the sample believed that more than half of the girls in their grade smoked. With regard to perceptions of adults, $45 \%$ of our respondents reported that more than half of adult women in the United States smoke. There were no significant differences in perceived prevalence between girls who were smokers and girls who did not smoke. Regardless of smoking status, adolescents greatly overestimated the prevalence of smoking among girls of their own age as well as among adult women.

These findings are consistent with those of previous studies that reported on teenagers' overestimates of smoking prevalence. They also point to the need for teaching young people about actual prevalence in tobacco prevention education programmes. What is left unexamined by these survey data is the level of smoking that girls believed to be so prevalent among their peers. In other words, when girls report that others "smoked", were they referring to "social" smokers or those individuals who smoke more regularly? In interviews, we found that saying someone was a smoker could refer to a range of behaviours, from having a cigarette at a party, to having one now and then, to smoking half a pack daily. Girls did not equate all of these smokers with tobacco dependency or having a cigarette "habit". Future surveys need to elicit more precise data on this topic.

CLASSIFICATION OF SMOKING: ADOPTING A TEENAGER'S PERSPECTIVE

With regard to smoking classification among adolescents, researchers have typically classified even those who smoke at the level of one cigarette per month as smokers. Previous studies have concluded that smoking at this level (at least monthly) increases the risk for adult smoking by a factor of 16 when compared with non-smoking. ${ }^{15}$ Thus, it has generally been concluded that even low-level smoking is a good predictor of future smoking behaviour.

In discussions with girls, it became clear that terms such as "smoker" and "non-smoker", which are typically used on surveys as well as in the expert literature, did not capture the range of adolescent smoking experiences. During in-depth interviews, we asked girls: "Have you smoked cigarettes since we last talked to you?", followed by: "Would you call yourself a smoker now?" Of those girls in our sample who reported smoking in the past few months, many stated that "I wouldn't really call myself a smoker". Therefore, on the survey, we included a category to reflect this behaviour pattern ('I'm not really a smoker but I'll have a cigarette every once in a while"). Similarly, several girls who reported smoking noted that they "just smoked when partying". Survey response choices were developed from interview data on teenage smoking classification to permit a more refined categorisation of smoking as defined by teenagers themselves. Table 2 shows the survey question and response choices that were used to determine girls' smoking classification.

Overall, $30 \%$ of our informants reported that they currently smoked, $7 \%$ were ex-smokers, and $63 \%$ of the sample were "non-smokers". For the purpose of the present analyses, girls are grouped into three categories: habitual smokers $(n=22)$, casual smokers $(n=39)$, and non-smokers $(n=129)$. Habitual smokers were those girls who reported "I smoke on a fairly regular basis but I don't need to"; and "I've got to have my cigarettes". Casual smokers were those who reported in the survey that "I'm not a smoker but I'll have a cigarette every once in a while" and "I just smoke when I'm partying". "Non-smokers" include those who said they "don't smoke" but exclude self-designated "ex-smokers". According to these descriptors, of the girls who currently smoked ( $n=61)$, $36 \%$ were included in the habitual smoker category and $64 \%$ were included in the casual smoker category.

To gather data on the quantity of cigarettes smoked, girls were asked: "How many cigarettes do you smoke a week?" The median number of cigarettes smoked by casual smokers was one per week, as compared with a median of 40 cigarettes per week for girls described as habitual smokers. The mean age 
Table 3 Responses to the survey question: "I started smoking because..."* $(n=61)$

\begin{tabular}{lrr}
\hline & $n$ & $\%$ \\
\hline I had a lot of stress in my life & 26 & 49 \\
I thought it was relaxing & 25 & 47 \\
My friends smoke & 21 & 40 \\
People in my house did & 8 & 15 \\
I wanted to be thinner & 6 & 11 \\
I thought people who smoke look cool & 4 & 8 \\
It made me look older & 2 & 4 \\
\hline
\end{tabular}

^Multiple responses were allowed.

of initiation for the casual smokers was 13.7 years old, as compared with a mean age of initiation for habitual smokers of 11.5 years old. Fifteen girls ( $7 \%$ of the sample) who described themselves as "ex-smokers" were eliminated from subsequent analyses because the level of previous smoking could not be determined and it seemed inappropriate to categorise them with the non-smokers.

\section{REASONS FOR SMOKING INITIATION}

In ethnographic interviews, we asked our smoking and non-smoking informants the following general question: "Why do you think some people choose to smoke?" Although answers varied across informants, the most frequent responses included smoking as a means to reduce stress and to relax, smoking because one's friends or parents did, smoking to look "cool", and smoking as a way to be thin. These comments were then developed into response choices for the survey question: "I started smoking because ...." This question was answered by 61 respondents in a special section of the survey designed for girls who considered themselves smokers. Responses for the question are indicated in table 3.

Smoking as a mechanism for reducing stress Almost half of the girls who smoked reported that they started smoking because they had a lot of stress in their lives, while $47 \%$ reported that they began smoking because they thought it was relaxing. Reading through the interviews of girls who were smokers, it is apparent that stress reduction and relaxation are important attributes of the smoking experience. Although girls did not experience this with their first cigarette, many girls explained how, after they started inhaling, "it started to calm my nerves and make me relax". Importantly, even girls who smoked rather infrequently ("I'm not a smoker but I'll smoke every once in a while") articulated this benefit of smoking.

What stressors were girls experiencing that led them to take up smoking? Where did girls get the idea that smoking would lead to stress reduction? For many of our informants, it was difficult to articulate reasons for being stressed. "Stress" was a specific ambiguous term, ${ }^{16}$ a catch-all for a wide range of feelings ranging from being overwhelmed, to being anxious, to being angry. Among those girls in our sample who were able to talk about stress-inducing situations, the following were described: family fights, the stress of fitting in or finding a group, and the stress of keeping up with schoolwork. One of our more articulate informants, whose parents smoked but was herself a non-smoker, described reasons why her peers smoked:

"People smoke because they want to be in with a group, they have problems that they think that the cigarettes will take away, like family, friends, you know ... not having friends. As far as family, you know, maybe they just don't get along with their parents. So they think the cigarettes will help solve it. It relaxes them, takes away the stress."

Girls-smokers and non-smokers-associated tobacco use with the reduction of stress, an empirical observation they made from watching their parents and relatives light up a cigarette as a way to relieve tension. Similar observations were gleaned from watching smoking behaviours on television and in movies. Cigarette advertisements also play up the theme of smoking as self-medication for stress. Girls' narratives were peppered with observations about the relief a smoker gets from inhaling and the frustration and tension caused by not being able to smoke when one is in need of a cigarette. As one girl explained, "There's just a lot of stress. I mean you stress out and you think, 'Oh God, a cigarette'." Cigarettes allowed girls to transfer the focus of their attention from their immediate problem, by giving one "something to do with your hands". In a time of crisis, a cigarette provides an opportunity to "think about something else", to fixate on a bodily sensation rather than on one's mental worries.

One of the ways in which girls-smokers and non-smokers-learned about the stress-relieving qualities of nicotine was by observing their mothers. Although many girls disliked their mothers' smoking and were well aware of the health risks associated with the behaviour, they also recognised that smoking paradoxically enabled their mothers to deal with the stressors of their everyday lives. The daughter's understanding of the reasons for her mother's smoking enabled her to silence her complaints temporarily, even in the face of personal dislike for smoking. Reasons for their mothers' stress ranged from coping with divorce and death, financial problems, difficulty in relationships, and other personal hardships. ${ }^{17}$

\section{Smoking as stress reduction: the family} environment

One stressor in girls' lives was their family environment. As one girl explained, "My family really upsets me, and when I get upset that's when I do it, 'cause it calms me down. ... I feel better after I do it." Another girl noted, "I always need to smoke when I've been around my Mom. She just really stresses me out." One informant, who called herself a casual smoker, described an incident which happened after she had an argument with her mother.

"I guess I was kinda down then and I went over to my friend's house. When I got in she was smoking and I just grabbed a cigarette and started smoking it. But I didn't finish it, 'cause it made me sick. But, I don't know, my friend says it really calms her down to smoke, so I thought I'd try it."

Notably, girls in this sample who smoked at the heaviest levels ("I've got to have my 
Table 4 Responses to the survey question: "With regard to cigarette smoking, which statement best describes your best girlfriend?"

\begin{tabular}{lrrrrrr}
\hline & \multicolumn{5}{c}{ Respondents'smoking status } \\
\cline { 2 - 7 } & $\begin{array}{l}\text { Non-smokers } \\
(n=129)\end{array}$ & \multicolumn{2}{c}{$\begin{array}{c}\text { Casual smokers } \\
(n=39)\end{array}$} & \multicolumn{2}{l}{$\begin{array}{l}\text { Habitual smokers } \\
(n=22)\end{array}$} \\
& $n$ & $\%$ & $n$ & $\%$ & $n$ & $\%$ \\
\hline She never smokes & 105 & 82 & 15 & 39 & 5 & 23 \\
She's a smoker & 17 & 13 & 21 & 54 & 16 & 73 \\
She quit smoking & 7 & 5 & 3 & 7 & 1 & 5 \\
\hline
\end{tabular}

$\mathrm{P}<0.0001 ; \chi^{2}=53.71 ; \mathrm{df}=4$

cigarettes") all described having stressful relationships with their parents. ${ }^{17}$ Each of these girls related similar stories about problems with their parents, mostly because of their poor performance in school and their parents' dislike of their friends. Beyond the relationship with their parents, there seemed to be a constellation of factors contributing to their stress. These girls tended to belong to some fringe group in the high school (such as "stoners", "mods"), and some experienced teasing at school about, for example, their unusual dress or their choice of friends. In addition, their stress may have been conflated with being in an addiction cycle: if they were unable to smoke, their level of stress was exacerbated.

\section{Smoking as rebellion}

Although few girls overtly described that they smoked to rebel against their parents, several girls noted that rebellion was a reason why other teenagers smoked. For example, one girl, talking about her best friend, said that the reason her friend smoked was because her Mom was very strict- "You know, the kind that never lets her do anything". Smoking, in effect, was one of the few things she could do. Even if she was not allowed to date, smoking with friends was a way to mark her group identity before and after school. Smoking was a behaviour that her parents could not control because it occurred outside the home. Similar findings have been reported among young Britons by Oakley et al, who note that cigarettes "may in part function both literally and metaphorically as a 'smokescreen' behind which young people are able to establish their own emerging adult identities beyond the parental gaze" (page 87). ${ }^{8}$

\section{Stress related to schoolwork}

Although not commonly noted, three informants described how cigarettes helped reduce the stress related to schoolwork. As one informant noted:

"When I am by myself and I'm doing my homework, then it usually stresses me out and I smoke more. So I'm sitting there and I realise I have no idea what's going on in my history class and that huge biology assignment is due, like, three weeks from now and it gets really bad and so I get nervous [pretends smoking a cigarette fast] and smoke a whole pack. I have done that once. I sat down to do my homework and smoked the whole entire pack of cigarettes doing my homework."

Another girl noted that during finals she was really stressed out and didn't sleep much, so that she could study. During this time, she smoked a lot more than usual. For these girls, smoking served as a form of self-medication to help relieve the stress associated with unfinished classwork. These cases are somewhat unusual, because most of the heavier smokers in our sample were not particularly conscientious students.

Smoking as the lesser of evils

Not uncommonly, the decision to smoke was seen as a better choice for coping with stress than taking other drugs. Girls noted that if they had to do something, cigarettes were actually the lesser of other potential evils. One girl explained this position:

"I don't know, it's [smoking] not as bad as drugs or anything but sometimes it makes you feel better and just gets rid of stuff you're feeling. I mean, I've done worse things than that with drugs."

Similarly, another informant rationalised her smoking behaviour as "really not that bad". In is a discussion of smoking with her friends, she of noted:

"I mean we smoke but we're not terrible, we don't have records at the police station, we don't ditch school, well a couple of times, but I mean we didn't even get caught. We don't do anything that we have a record for or anything, but smoking ... well that's the only bad thing that we do."

\section{FLUCTUATIONS IN SMOKING}

The range of examples cited about smoking as a strategy for stress reduction was a reason for both smoking initiation as well as continuation. During interviews, it became clear that girls who smoked fluctuated in their level of tobacco use. In the survey, therefore, we asked the following question about the context of smoking (for which multiple responses were allowed): "When are you most likely to smoke more?" Of the girls who smoked ( $n=61), 60 \%$ responded "when I'm stressed", $46 \%$ reported "when I'm angry", and $30 \%$ reported "when I'm lonely". Other answers included "when I'm nervous" (27\%), "when I'm bored" (20\%), "when I'm happy" (11\%), and "when I'm hungry" (9\%).

\section{SMOKING WITH GIRLFRIENDS}

It has been consistently reported that having best friends who smoke increases the 음 likelihood of adolescent smoking. ${ }^{18}{ }^{19}$ Indeed, $D$ the association between smoking initiation and friends' smoking is stronger for girls than boys, N suggesting that girls may be more susceptible to social influences than boys. ${ }^{20}$ To ascertain the commonality of smoking among friends in our sample, the question was asked: "With regard to cigarette smoking, which statement $\stackrel{0}{\subset}$ best describes your best girlfriend?" Results are $\stackrel{D}{\rightarrow}$ shown in table 4 .

Of the girls who were non-smokers, $82 \%$ described their best girlfriend as also being a $\stackrel{\mathbb{D}}{\circ}$ non-smoker. Almost three-quarters of the girls $\mathbb{D}$ in the habitual smoker category described their best friend as a smoker. Among casual smokers, $54 \%$ said their best friend smoked. Thus, the heavier the level of smoking among our adolescent informants, the more likely it was that their best girlfriend also smoked.

Survey responses show that $57 \%$ of girls in our sample had tried smoking cigarettes. In response to the question "I tried my first 
cigarette with . ..", more than $70 \%$ reported that they had tried with a girlfriend whereas $16 \%$ had tried by themselves. Less than $5 \%$ had tried with either a boyfriend, their mother/ father, or a sibling. Thus, both experimentation and continuation of smoking appear to be connected to having friends who smoke.

\section{SMOKING TO LOOK "COOL"}

Although only $8 \%$ of girls responded on the survey that they had "started smoking to look 'cool"' (table 3), girls' interview narratives are replete with comments about how they thought smoking "looked cool" when they observed others their age doing it. As one girl who smoked explained:

"When you're doing it, I guess, I admit I used to feel just cool holding a cigarette, sitting there you feel cool. Afterwards, though, you feel sick so I don't know why I did it. I think everyone thinks they look awesome or something when they're smoking and that's why they do it."

For those girls who began smoking in elementary school, smoking cigarettes was viewed as a way to be accepted by an older crowd. One girl explained how she had started smoking in the fourth grade (9-10 years old) because she hung out with all the older girls, and as they smoked, she smoked. She noted that she had done it "mainly just to be cool".

In addition to being "cool", smoking cigarettes was also described as "fun". As one girl explained:

"Sometimes I like it 'cause it's kind of a fun thing to do, I mean, people say how disgusting it is and stuff like that, but, I mean I think it's disgusting when people constantly do it. I think chewing is sick, I mean, I think I'll try chewing at some point. ... It'd be fun to do. ... And I guess smoking kinda makes me feel older, but I don't say

'Hey, look at me I'm cool' or something like that. Ya know what I mean?"

Some girls described just how difficult it was for them to continue smoking after trying it for the first time because they thought it was so disgusting. This is consistent with previous findings that a child's first cigarette is rarely pleasurable. ${ }^{21}$ In a study of smoking uptake, Friedman et al found that the number of unpleasant physiological reactions reportedfor example, dizziness and coughing-was initially high but significantly decreased over the first three smoking incidents. ${ }^{22}$

Girls in our study who persisted and eventually became smokers often mentioned how they kept trying because it looked "cool". One girl explained, "I think a lot of people just started because they thought 'Oh, I'll be cool', and they ended up getting addicted." Another girl, who had recently quit smoking, sarcastically remarked, "Yeah, lung disease, what a cool thing to have. I started and then after a while I was like, 'I'm not going to kill myself to be popular.'" Unfortunately, this level of insight was not common among our informants who smoked.

Part of looking "cool" while smoking was not coughing and appearing like a novice when you did it. One girl explained how on the weekends, when her parents were out, she would steal her mother's cigarettes and practice smoking in the solitude of her own home. She explained:

"I go into the very back room and open all the doors and windows and I still gag. If I decide I want to smoke in front of all my friends, I don't want to gag in front of them. It's like self pressure. It's like, I kinda want to smoke, but I don't 'cause I sit there and tell them not to smoke so I can't really smoke, so I smoke at home."

Her term "self pressure"-as distinct from peer pressure-may be an appropriate term to describe the behaviour of many other girls her age. Rather than feeling pressure from others, they may experience internal pressure to behave as others around them do.

Two important points emerge from girls' narratives about smoking with friends. First, it appears that social risk-that is, the risk of being made fun of or being excluded for not smoking-may weigh more heavily on teenagers' minds than issues of physical risk. Second, smoking is viewed as a behaviour that can be "tried on" in the same way as one assumes a new identity through altering one's clothes or changing one's crowd of friends. It became clear in talking with teenagers that their understanding of the addictive nature of nicotine was linked to chain smokers. Girls who were casual smokers and non-smokers would describe how they thought smoking "a lot" was "really gross", but that it would be okay to "try it for a little while". In the quote above, our informant, a 15-year-old who described herself as a casual smoker, differentiates between smoking being "disgusting when you constantly do it" but "fun if you do it just a little". In interviews, the commonality of the statement "I smoke but I'm not addicted or anything", led to the survey response choice "I smoke on a fairly regularly basis but I don't need to." Descriptions such as this make it obvious that the concept of gradual addiction to nicotine may be poorly understood by those who may be smoking at low levels or have not yet tried to quit.

PEER PRESSURE: A RECONSIDERATION

Although the influence of peers on smoking initiation is well-recognised in the expert literature, ${ }^{23}{ }^{24}$ relatively little is known about how peer influence is perceived by teenagers themselves. The term "peer pressure" is often reified and discussed as if it were a social fact exerting a constant force in the life of teenagers. Use of the term in the literature often suggests that teenagers experience direct pressure to smoke when, in fact, social influences may be subtle and are experienced in a variety of ways depending on context and the individuals involved.

Several earlier studies concluded that the notion of peer pressure may be overly simplistic. ${ }^{22-26}$ Newman observed that, although teenagers did admit that there were pressures to smoke, these were "more subtle than the overt type of peer pressure described by adults" (page 146). ${ }^{26}$ Chassin, Presson, and Sherman noted that adolescents are not "passive recipients of external forces that promote smoking initiation" (page 138) and 
suggested that there is a bi-directional relationship between cigarette smoking and peer smoking models. ${ }^{15}$ The manner in which social influence is perceived by teenagers has not been adequately assessed and represents a topic that has important implications for smoking prevention programmes that teach refusal skills to adolescents.

In response to the survey question about reasons for smoking initiation (see table 3), $40 \%$ of girls cited friends' smoking as a factor. As one 10th-grade girl described:

"I was with my two best friends--'cause I had two best friends in eighth grade-and it was like everybody else was smoking. We're like 'Hey, let's try it', you know. So we started smoking, well, you know, pretending that we were smoking and we just kept on and then we were really smoking and then we kept smoking and smoking. Now we're like hooked on smoking and we can't quit."

Interestingly, however, when asked if there was pressure from friends to smoke, most girls denied that they had actually experienced peer pressure to try a cigarette. One girl's response seemed to typify those of others:

"Well, no it's not like peer pressure, but when your friends do it, it kind of just makes you want it, like it's the same way with eating, you know." Girls were more likely to explain that because their friends smoked and they were around them, they "just decided to try it". One girl noted, "I just feel like I want to smoke when people around me smoke but I don't know why. It's just a thing that you do." Other girls explained:

"I smoke like whenever my friends are doing it. It's not like peer pressure or anything like that, you know, it's like, you know, if they're here and they're smoking, you know, and it's like, I don't know, it's like 'Well, you know, can I have one?' And they're just like 'Yeah'.

"It's like 'monkey see, monkey do'. You just see your friends doing it and you want to do it too."

Similarly, one informant, who had tried smoking but decided she didn't like it, explained that she never felt pressure to smoke. She noted:

'Like I don't think I've ever been pressured into doing anything. I mean someone will ask and I'll say no or yes or whatever. Then they'll just go 'OK'.... I mean people make it sound like, oh, like every person gets pressured into smoking when it's really, well they just make it sound so drastic. It's really not. Or at least I don't think it is. It's more like you're just scared like they'll make fun of you, or like you want to fit in, that's why you do it."

Once a girl had been seen smoking a couple of times, she was often classified as a smoker by others in her group and would be offered cigarettes, even without her asking. One girl provided a description of her smoking experience with her peers:

"When I started I was at a party, with a bunch of other people and I don't know, I was, I'd been drinking so yeah, it was like ' $O K$, I'll have a cigarette'. Next thing I know, you know, next time I went out I was like 'It'd be okay to have one of these again'. And the next thing I knew every time I'd go out someone's like 'Oh here, she smokes. Have a cigarette'. I'm like ' $O K$ '."

Thus, although girls may not experience pressure to begin smoking, once labelled as a smoker there may be encouragement or expectations to join others in smoking as a social act. 응 In this sense, there may be social influences to continue smoking.

SMOKING AT PARTIES

For those girls who described themselves as casual smokers, smoking was often something 등 to do at a party. The following interaction was $\frac{\bar{\sigma}}{\bar{s}}$ noted between a 10th grader, who described $\vec{\nabla}$ herself as a social smoker, and an interviewer:

Denise: "I'm not addicted to it and I can live without it. I can go for months without a ciga- $\vec{\circ}$ rette and not have any craving for it. But if I'm $\overrightarrow{\vec{\omega}}$ around somebody that has a cigarette I'll have $\stackrel{\sigma}{\omega}$ one. It kind of completes the party thing."

Interviewer: "It completes the party thing? What do you mean?"

Denise: "I don't know, I mean I just can't ô

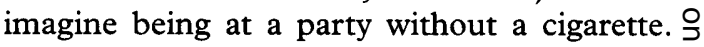
I'm not at all addicted to them, and I went most of the summer when I was with my Dad without them. I don't go into withdrawal. $\overparen{\varnothing}$ Whenever I can get one it's fine, it doesn't $\frac{3}{8}$

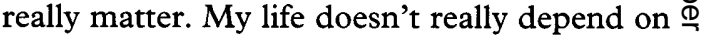
it. . . . Whenever there's one I smoke it. . . I I $\vec{\bullet}$ figure I'm going to die anyway, I might as well be happy. You know, it kind of gives you a buzz."

Some girls described how smoking "was like a ritual" that kids did at parties. One informant noted, "You know, if you're drinking then $\frac{\mathrm{D}}{\mathrm{O}}$ you've got to be smoking." Interestingly, one girl explained that she had heard that smoking $\frac{0}{3}$ and drinking went together because after the $\vec{\partial}$ buzz of alcohol wore off, "taking a hit off a cigarette" brought it back. Indeed, a particularly strong relationship of alcohol use with cigarette smoking has frequently been noted in the literature. ${ }^{27}$ Whether nicotine use among habitual alcohol drinkers represents an $\mathrm{O}$ effort to enhance the effects of alcohol, $\underline{\overrightarrow{0}}$ whether both represent self-medication, or $\frac{}{\sigma}$ whether both represent vulnerability to drug 3. dependence remains to be determined. ${ }^{28}$

Several girls noted that although they liked $₹$ smoking, they did not want to become 을 addicted because then they would not get the same kind of "buzz". In a similar vein, another girl explained how it was better not to be a chain smoker so you could retain a more consistent high:

"Smoking gives you like a high feeling, like it $\stackrel{N}{\omega}$ makes you dizzy and stuff. It's just that feeling. A lot of my friends aren't like chain smokers, they'd 0 be like I do, it just gives you like a feeling and I think they like it. But they know if they get $\stackrel{?}{+}$ addicted they're not going to get it [the feeling] $T$ all the time, so they don't want to get addicted." Girls who were casual or habitual smokers were significantly more likely to drink than $\stackrel{\mathbb{Q}}{\varrho}$ girls who were non-smokers. Fifty-one per cent of non-smokers reported that they never drank alcohol, compared with $18 \%$ of smokers. With regard to frequency, $30 \%$ of girls who were habitual smokers reported that they drank $\stackrel{0}{\partial}$ alcohol one or more times per week, as compared with $7 \%$ of casual smokers and $3 \%$ of non-smokers. Thus, not only were girls reporting that smoking went with drinking, but 
Table 5 Responses to the survey question: "Which of the following statements do you think will describe you when you are in the 12th grade?" $(n=190)$

\begin{tabular}{lrrrrrr}
\hline & \multicolumn{5}{c}{ Respondents'smoking status } \\
\cline { 2 - 7 } & \multicolumn{2}{c}{$\begin{array}{l}\text { Non-smokers } \\
(n=129)\end{array}$} & $\begin{array}{l}\text { Casual smokers } \\
(n=39)\end{array}$ & \multicolumn{2}{l}{$\begin{array}{l}\text { Habitual smokers } \\
(n=22)\end{array}$} \\
& $n$ & $\%$ & $n$ & $\%$ & $n$ & $\%$ \\
\hline $\begin{array}{l}\text { I'll smoke } \\
\text { I'll have tried, but decided }\end{array} \quad 3$ & 2 & 22 & 58 & 18 & 82 \\
$\quad$ not to smoke & 34 & 26 & 14 & 36 & 1 & 4 \\
I'll have smoked a lot and quit & 1 & 1 & 2 & 5 & 3 & 14 \\
I'll never have smoked & 91 & 71 & NA & NA & NA & NA \\
\hline
\end{tabular}

$\mathrm{P}<0.0001 ; \chi^{2}=136.1 ; \mathrm{df}=6$.

NA $=$ not applicable.

those who smoked were more often in party situations where that behaviour occurred.

Smokers were also significantly more likely to use drugs (other than alcohol, including marijuana) when compared with non-smokers. Of those girls who were habitual smokers, $60 \%$ reported that they did drugs "once in a while", $25 \%$ used them "pretty often", and $15 \%$ tried them only once. Among casual smokers, more than half had never tried drugs. Of those girls who had tried drugs, $25 \%$ used them "once in a while" and $25 \%$ tried them only once. Among non-smokers, only $13 \%$ had tried drugs. Of those girls who had tried drugs, $9 \%$ had tried them once, while $4 \%$ used them "once in a while".

\section{BRAND PREFERENCES}

Although the practice of sharing cigarettes was commonplace among casual and habitual smokers, brand preferences became established once girls began buying their own packs. In response to the question "What brand do you smoke?", $64 \%$ of girls in the sample smoked Marlboros, $21 \%$ smoked Camels, $11 \%$ smoked GPC, $2 \%$ smoked clove cigarettes, and $2 \%$ smoked "whatever they could find". Some casual smokers switched brands, but this was usually between Marlboro and Camels. One informant, whose brand preference fluctuated between these two, commented how, if there was a 2 -for-1 special, or "a really cool" gift offer like a lighter or a jacket, she would purchase that brand to save up for the "free" gift. The extent to which promotions are a motivating factor in brand preference among adolescents needs further exploration.

Girls in the sample who smoked GPCs were those smoking at the highest level, a decision clearly dictated by cost. Some casual smokers commented that GPCs were smoked by "scummier" people, or "those who really, really need a cigarette" or "those who just don't have enough money to buy any other brand". One casual smoker noted, "I mean GPCs are like so cheap, so you just figure they're a cheaper product. I mean you wonder what's really in them."

Brand-switching was adopted by some habitual smokers as a means to reduce their smoking. One informant who was smoking a pack a day had switched from Marlboro Reds to Marlboro Lights as part of her effort to quit. Another girl, who had adopted a similar strategy, explained:
"I mean my smoking, it has grown. I remember when I used to smoke like one or like two cigarettes every few days, you know what I mean? And then all of a sudden it just kept going and going and now I realize I really HAVE to smoke. I'm smoking lighter though. I used to smoke Camels, and now I'm smoking Marlboro 100 Lights, so it's like lighter. I know it's not still the best thing, you know."

PERCEPTIONS OF SELF AS SMOKER IN THE FUTURE To assess future plans with regard to smoking behaviour, we asked girls to respond to the survey question: "Which of the following statements do you think will describe you in 12th grade?" Table 5 provides the response choices and informants' answers.

More than a quarter of the girls (26\%) who were non-smokers in the sample believed that they would have experimented with smoking by the 12th grade (ages 17-18). Of the girls who were current smokers, almost $60 \%$ of casual smokers and more than $80 \%$ of habitual smokers reported that they would still be smokers in the 12th grade, with fewer than a third of the current smokers reporting that they would quit. Notably, of those current smokers who reported that they would still be smoking in the 12 th grade, approximately $70 \%$ reported that they had started smoking because it helped to relax them and reduce their stress. Data reported earlier in this paper about the increase in smoking in relation to being stressed, angry, and nervous speak to the issue of stress reduction as a factor in the continuation of smoking.

Several studies have noted that many smokers want to quit but are unable to do so. ${ }^{29}$ To assess our informants' perceptions of quitting, they were asked if they agreed or disagreed with the statement: "If a smoker really wants to, it is easy to quit". Responses show that approximately $85 \%$ of smokers and nonsmokers disagreed with this statement. Fifteen per cent of girls in all three categories agreed that it was easy to quit, if the smoker really wanted to.

\section{PERCEPTIONS OF HEALTH RISKS}

Previous studies have concluded that adolescents who smoke typically are less concerned with long-term health risks of smoking when compared with non-smokers. For example, in one study of adolescents, $21 \%$ of smokers (compared with $3 \%$ of those who never smoked) said they believed that it is safe to smoke for only a year or two. ${ }^{29}$ To assess this issue among our informants, a survey question and response categories were developed from issues that emerged during ethnographic interviews. The question and response choices are shown in table 6.

In response to the question "I think smoking is . . .", $91 \%$ of non-smokers endorsed the statement that "smoking is harmful to a smoker's health", as compared with $74 \%$ of casual smokers and $59 \%$ of habitual smokers. Thus, it appears that as the level of smoking increases, girls are significantly less likely to agree that it is harmful. Almost a quarter of the casual smokers endorsed the statement "Smoking is 
Table 6 Responses to the survey question: "I think smoking ...."

\begin{tabular}{|c|c|c|c|c|c|c|}
\hline & \multicolumn{6}{|c|}{ Respondents'smoking status } \\
\hline & \multicolumn{2}{|c|}{$\begin{array}{l}\text { Non-smokers } \\
(n=129)\end{array}$} & \multicolumn{2}{|c|}{$\begin{array}{l}\text { Casual smokers } \\
(n=39)\end{array}$} & \multicolumn{2}{|c|}{$\begin{array}{l}\text { Habitual smokers } \\
(n=22)\end{array}$} \\
\hline & $n$ & $\%$ & $n$ & $\%$ & $n$ & $\%$ \\
\hline \multirow{4}{*}{$\begin{array}{l}\text { Has more psychological benefits } \\
\text { than physical risks } \\
\text { Is okay because we're going } \\
\text { to die anyway } \\
\text { Is harmful to a smoker's health } \\
\text { Is okay as long as you don't } \\
\text { smoke too much }\end{array}$} & 9 & 7 & 1 & 3 & 2 & 9 \\
\hline & 2 & 2 & ND & ND & 6 & 27 \\
\hline & 117 & 91 & 29 & 74 & 13 & 59 \\
\hline & 1 & 1 & 9 & 24 & 1 & 5 \\
\hline
\end{tabular}

$\mathrm{P}<0.0001 ; \chi^{2}=59.16 ; \mathrm{df}=6$

$\mathrm{ND}=$ no data.

Table 7 Responses to the survey question: "I don't smoke because..."* $(n=205)$

\begin{tabular}{ll}
\hline & $\%$ \\
\hline It's bad for my health & 92 \\
It's gross & 75 \\
It doesn't look good & 61 \\
My parents would kill me & 44 \\
It's too expensive & 28 \\
My friends don't smoke & 23 \\
It's against my religion & 12 \\
\hline
\end{tabular}

^Multiple responses were allowed.

okay as long as you don't smoke too much", as compared with $5 \%$ of habitual smokers and $1 \%$ of non-smokers. With regard to the response category "Smoking is okay because we're going to die anyway", it is interesting to note that more than a quarter of habitual smokers endorsed this statement. The following quote by a girl whose boyfriend had been haranguing her to quit smoking exemplifies this attitude:

"He says 'You shouldn't smoke, you're going to die'. But, I'm going to get old and die anyway. I want to enjoy life. I want to live and not worry about it! It may sound really stupid but I just want to do what I want to do."

Previous studies have suggested that young people who begin to use tobacco do not understand the addictive nature of nicotine. ${ }^{2}$ Many of the girls in the study who realised that smoking was not healthy thought casual smoking was okay. Among this group, there was a tendency to believe that it was possible to control one's consumption without great difficulty. One 11th grader, who described herself as a casual smoker, noted:

"I don't really see smoking as that big a thing. I don't do it that often. I don't do it on a regular basis or even feel the need that I have to do it."

When asked if she thought smoking was harmful if she didn't do it too much, she replied:

"I'm not saying it's not harmful for me, but I just don't think I'll have a problem with it later on in life, just 'cause I know how I am. I could stop when I wanted to. If it got out of hand, like if I smoked one or two cigarettes every day, I'd stop." This example highlights the theme of control which runs through the narratives of many of our informants. Some girls described how they were not "really addicted, which was kinda cool". What emerged was a sense of how they could control their cigarettes, rather than have their cigarettes control them. In discussions about addiction, some girls described having family members who smoked and drank but "weren't really addicted to anything". Others talked about parents who smoked but "weren't sick or anything" or who "didn't even have a 응 cough". In effect, girls thought this conferred a $\bigcirc$ level of immunity on them in terms of their own smoking behaviour.

\section{REASONS FOR NOT SMOKING}

It is important to note that $70 \%$ of girls in this sample were non-smokers. To assess why they 흠 had made this decision, we asked the survey $\frac{\omega}{\vec{D}}$ question shown in table 7 , for which multiple $\stackrel{\mathbb{Q}}{\varrho}$ responses were allowed.

In interviews, it was found that discussions $\overrightarrow{0}$ with friends about smoking sometimes led to decisions to discontinue the behaviour. One $\vec{\omega}$ girl, who had experimented with smoking in $\vec{\rho}$ the eighth grade, noted:

"We used to smoke in eighth grade but we quit. We talked about it and found out that none of us really liked it, but we just smoked 'cause everyone of else did. So we all quit."

Another frequent comment about smoking was that it was "gross" and bad for health, as exemplified by the following remarks:

"I smoked a couple of times and I don't know 3 why I did it. I felt kind of gross, actually. I felt $\stackrel{\mathbb{Q}}{-}$ kind of sleazy. I felt really gross, 'cause you could smell it on me. Stuff like that, I don't know. I'm glad I stopped though. I guess I didn't really start though. It was just like a week.

“No, I think it's gross. I mean I've tried it and I don't like it. It's the smell. It stays with you. I don't like it. There's no reason for smoking.

"I personally won't have anything to do with anyone who smokes. I think it's bad for your health, I think it's a bad habit. I think it smells sick. I think it irritates me."

In individual interviews, many girls who were non-smokers described their dislike for smoking, particularly if they had grown up with parents who smoked. Several of these girls were not willing to express their anti-smoking sentiments in group settings for fear of being unpopular among smoking teenagers. It may be important for prevention educators to recognise that such sentiments exist among teenagers and to explore how anti-smoking sentiments can be channelled into prevention efforts. ${ }^{30}$

\section{Discussion}

In this sample of adolescent girls, it was found $N$ that $30 \%$ of girls currently smoked, $7 \%$ were $N$ ex-smokers, and $63 \%$ were "non-smokers". N The sample was predominately white $(68 \%)$ and Mexican American (13\%), and 13\% of the girls did not categorise themselves into an ethnic group. The remaining $6 \%$ of girls were Asian American and Native American. There were no significant differences across ethnic groups with regard to smoking status, nor were there significant differences in girls' smoking in relation to levels of parental education.

Among this population of adolescent females, smoking was identified as a resource for stress reduction, a finding that substantiates previous research. ${ }^{31}{ }^{32}$ Although this study was not designed to identify teenage stressors, several stress-inducing situations were identified, including family environment, social relations with classmates, and schoolwork. As a coping 
mechanism, lighting up a cigarette alone or among friends created a social space in which girls could "calm down and relax". Future studies need to examine smoking as self-medication among adolescents, a topic that has recently been discussed in relation to adult women. ${ }^{33}{ }^{34}$ In addition, research on adolescence needs to be conducted on smoking uptake and continuation in relation to levels of stress and the availability of other coping resources. Attention also needs to be paid to what images support the association of smoking with relaxation and the role these images play in fostering smoking as a form of self-medication. Smoking prevention and cessation programmes need to address and counter the smoking/relaxation association by calling attention to the addiction cycle that sustains this association.

Beyond stress reduction, smoking a cigarette was found to facilitate social interaction by providing an opportunity for girls to engage in sharing and reciprocity as a means of establishing a relationship. Although teenagers in this study recognised that certain social environments were more conducive to smoking than others (such as parties, or while drinking), they were resistant to the fact that there is pressure to initiate smoking. To say that it was "just something I wanted to do" or "I just felt like doing it when I was around my friends" was different than saying there was peer pressure. Using the term "peer pressure" might imply that the girl had succumbed to her friends or that her decision to smoke was not entirely her own. Denying peer pressure may have served as an affirmation of her own agency.

From a developmental perspective, it is important to consider that the establishment of an autonomous self is one of the hallmarks of adolescence. Adopting cigarette smoking as a symbol of independence and autonomy is perhaps not surprising, because these are associations clearly portrayed in advertising. On billboards and in magazines that have wide appeal to adolescent females-for example, Glamour, Mademoiselle, Rolling Stone-smoking is associated with adult themes such as rugged individualism (the Marlboro man), as women's independence (Virginia Slims), and as a marker for social status (adulthood). These advertisements may have increased salience for adolescents who are experimenting with different identities. Tobacco prevention programmes need to focus on fostering a sense of agency among young people rather than dwelling on peer pressure or social influences, which turn teenagers into passive objects influenced by others. Although attention to peer pressure may be appropriate in prevention programmes in elementary schools, such a focus may be far less effective among young people in middle school (ages 11-14)..$^{30}$

The theme of independence permeated girls' narratives about their own smoking behaviours. Some of the girls who were casual smokers did not believe that they would become addicted to nicotine, although they were aware of the health consequences of smoking. This thinking is exemplified by one informant who described how smoking was "kinda fun" but "disgusting when people constantly do it". In her narrative, as well as that of many other girls, there is a decisive lack of understanding of the powerful grip of nicotine addiction. Consonant with notions of adolescent autonomy, girls projected the image that they could control their cigarettes rather than have their cigarettes control them. This issue raises troubling questions about the ability of teenagers in early and mid-adolescence to make informed decisions about smoking.

Although teenagers may not articulate peer pressure to initiate smoking, they do describe peer pressure in relation to quitting. Thus, when teenagers who are occasional or regular smokers try to quit, the fact that they have been labelled by their peers as smokers may make the process a difficult one. Given the pervasive image that smoking is "cool", it may be strategic for smoking cessation programmes to create a similar image of quitting as "cool" Cessation programmes could teach adolescents how smoking is a form of dependence (both on cigarettes and, more broadly, on tobacco companies) and build on the theme of independence and personal decision making in fostering quitting.

In ethnographic interviews and in response to survey questions, we found that most girls who smoked did not consider themselves to be smokers. It needs to be recognised that gloss terms like "smoker" and "non-smoker" do not adequately capture the smoking behaviour adopted by many teenagers who may experiment with tobacco but do not perceive themselves to "really smoke". Although widely used questions on national surveys, such as "How many cigarettes did you smoke in the past 30 days?", generate important statistics on teenage smoking, they reveal little about the contexts in which teenage smoking occurs or how the meaning of smoking shifts across social environments. It is critical that we begin to understand these issues more thoroughly to inform prevention and cessation programmes.

This research was supported by NIH Grant No HD24727 from the National Institutes of Health, National Institute of Child the National Institutes of Health,
Health and Human Development.

1 Kann L, Warren CW, Harris WA, et al. Youth risk behavior surveillance: United States, 1995. In: CDC surveillance summaries, 27 September 1996. MMWR 1996;45(SS4): $1-84$.

2 US Department of Health and Human Services. Preventing tobacco use among young people. A report of the Surgeon General, 1994. Atlanta, Georgia: Public Health Service, Centers for Disease Control and Prevention, Office on Smoking and Health, 1994 (US Government Printing Office No S/N 017-001-00491-0.)

3 US Centers for Disease Control and Prevention. Indicators of nicotine addiction among women-United States, of nicotine addiction among wom

4 Flay B, Petraitis J. A review of theory and prospective research on the causes of adolescent tobacco onset. Unpublished paper for the Robert Wood Johnson Foundation, November 1993.

5 Moncher MS, Holden GW, Schinke S. Psychosocial correlates of adolescent substance use: a review of current etiological constructs. Int $\mathcal{F}$ Addict 1991;26:377-414.

6 Harding G. Adolescence and health: a literature review. In: Health education and young people. London: Thomas Coram Research Unit Occasional Paper No 9, 1989.

7 Millstein S. A view of health from the adolescent's perspective. In: S Millstein, A Petersen, E Nightingale, eds. Promoting the health of adolescents: new directions for the twenty-first century. New York: Oxford University Press, 1993:97-118. 
8 Oakley A, Brannen J, Dodd K. Young people, gender and smoking in the United Kingdom. Health Prom Int 1992;7:75-88.

9 Savin-Williams R. Adolescence: an ethological perspective. New York: Springer-Verlag, 1987.

10 Chassin L, Presson CC, Sherman SJ, Corty E, Olshavsky RW. Self-images and cigarette smoking in adolescence. RW. Self-images and cigarette smoking

11 Leventhal $H$, Fleming $R$, Glynn $K$. A cognitivedevelopmental approach to smoking intervention. In: $S$ Maes, CD Spielberger, P Defares, IG Sarason, eds. Topics in health pyschology. New York: Wiley, 1988:79-105.

12 Chassin L, Presson C, Sherman S, Corty E, Olshavsky R. Predicting the onset of cigarette smoking in adolescents: longitudinal study. $\mathcal{F}$ Appl Soc Psychol 1984;14:224-43.

13 Collins L, Sussman S, Mestel-Rauch J, et al. Psychosocial predictors of young adolescent cigarette smoking: a sixteen-month, three wave longitudinal study. $\mathcal{F}$ Appl Soc Psychol 1987;17:554-73.

14 Sussman S, Dent CW, Mestel-Rauch J, Johnson CA, Hansen WB, Flay BR. Adolescent nonsmokers, triers, and regular smokers' estimates of cigarette smoking prevalence: when do overestimations occur and by whom? $\mathcal{F}$ Appl Soc Psychol 1988;18:537-51.

15 Chassin L, Presson C, Sherman S. Social psychological contributions to the understanding and prevention of adolescent cigarette smoking. Personality Soc Psychol Bull 1990;16:133-51.

16 Nichter $M$. The language of illness, contagion, and symptom reporting. In: Mark Nichter, ed. Anthropology and international health: South Asian case studies. Dordrecht: Kluwer Academic, 1989:85-124.

17 Nichter M. Gender, stress, and smoking: maternal influences on their adolescent daughters. Paper presented at the meetings of the American Anthropological Association, November 1996, San Francisco, California.

18 French SA, Perry C. Smoking among adolescent girls: prevalence and etiology. $\mathcal{F}$ Am Med Wom Assoc 1996; 51(1\&2):25-30

19 McNeill A, Jarvis M, Stapleton J, Eiser J, Gammage P, Gray E. Prospective study of factors predicting uptake of smoking in adolescents. $\mathcal{F}$ Epidemiol Community Health 1989; 43:72-8.

20 Waldron I, Lye D, Brandon A. Gender differences in teenage smoking. Women Health 1991;17:65-90.

21 Bewley D, Beulah R, Bland J, Harris R. Factors associated with the starting of cigarette smoking by primary school children. Br F Prev Soc Med 1974;28:37-44.
22 Friedman LS, Lichtenstein E, Biglan A. Smoking onset among teens: an empirical analysis of initial situations. $-1-1$
Addict Behav 1985;10:1-13.

23 Flay B, Hu F, Siddiqui $\mathrm{O}$, et al. Differential influence of $\bigcirc$ parental smoking and friends' smoking on adolescent initiation and escalation of smoking. $\mathcal{f}$ Health Soc Behav 1994;35:248-65.

24 Lau R, Quedrel MJ, Hartman KA. Development and change of young adults' preventive health beliefs and behavior: influence from parents and peers. 7 Health Soc $\overline{0}$ Behav 1990;31:240-59.

25 Curry SJ, Peterson AV, Mann SL. Investigation of first opportunities to use cigarettes and smokeless tobacco. $\frac{\bar{S}}{\bar{D}}$ Health Educ Res 1989;4:27-34.

26 Newman IM. Capturing the energy of peer pressure. $f \frac{Q}{\text { School Health } 1984 ; 54: 146-8 \text {. }}$
S

27 Jessup M. Nicotine: a gateway drug? 9 Am Med Wom Assoc 1996;51(1\&2):21.

28 Pomerleau CS, Berman BA, Gritz ER, Marks $\pi$, Goeters S. Why women smoke. In: RR Watson, ed. Addictive behaviors in women. Totowa, New Jersey: Humana Press, 1994:3971.

29 Allen KA, Moss GA, Giovino D, Shopland R, Pierce JP. ? Teenage tobacco use data. Estimates from the Teenage Attitudes and Practices Survey, United States, 1989. Advance data no N 224. Hyattsville, Maryland: National Center for Health or Statistics, 1993:9.

30 Nichter M, Trowbridge A, Van Sickle D. Perceptions of smoking among youth: a report of focus group interviews with elementary and middle school students. Prepared for the School-Based Tobacco Prevention Education Program, Pima County, Arizona. Arizona Department of Health Services, 1997.

31 Pierce J, Farkas A, Evans N, et al. Tobacco use in California (\$) 1992. A focus on preventing uptake in adolescents Sacramento, California: California Department of Health Services, 1992.

32 Shiffman S, Wills T. Coping and substance use. London: Academic Press, 1985.

33 Graham $\mathrm{H}$. When life's a drag: women, smoking and disadvantage. London: Department of Health, 1993.

34 Greaves L. Smoke screen: women's smoking and social control. Halifax, Nova Scotia: Fernwood, 1996. 